\title{
Territory attractiveness index IVAOS
}

\author{
Alena G. Obolenskaya, and Irina A. Simonova \\ Ural State Pedagogical University, 620017, Kosmonavtov str. 26, Ekaterinburg, Russia
}

\begin{abstract}
The article proposes the IVAOS index for assessing the attractiveness of the territory. it is an important factor in regional development and attractiveness of the territoryюThe development of the index is due to the fact that a modern city is a specific (in the economic and socio-cultural sense) formation: it, as a rule, combines objects from different eras, broadcasting different stylistic, ideological, aesthetic and functional modes. The polymorphism and spontaneity of space do not always make it possible to determine the correct directions of development that meet the specific needs of residents and contribute to an increase in the well-being of the territory. The development of cities and the image of the city of the future do not coincide in the minds of the modern inhabitants of the megalopolis. The modern city deprives its inhabitants.
\end{abstract}

\section{Introduction}

One of the important factors of regional development is the attractiveness of territories in all its aspects: investment attractiveness and the desire of people to live on the territory and do business here [1]. This provision applies to all settlements in the regions, but is especially important for cities. A modern Russian city is a specific (in the economic and socio-cultural sense) formation: as a rule, it combines objects from different eras, conveying different stylistic, ideological, aesthetic and functional modes. Polymorphism, and in some places the spontaneity of such a space, does not always allow us to determine the correct directions of development, corresponding to both the specific needs of direct users and an increase in the general welfare of the territory. Thus, the development of cities and the image of the city of the future do not always coincide in the minds of the modern youth of the metropolis. The modern city deprives residents. In anticipation of new industrialization, digitalization, young people want to see around a modern infrastructure, a robotic environment with good aesthetics. However, municipalities cannot quickly and fully finance the rapid and costly renovation of urban space. Landscape design rules have long been accepted, but not always respected, and also provoke aggression and destructive actions. And residents, as shown in Weber's study surveyed 381 responses received, the top five

mostimportantneighborhoodconcernswerecrime,propertytaxes, vandalism,propertyvalues, and places for outdoor recreation (Weber S. et al., 2017) [2].

In addition, today it is necessary to think about how business objects, including industrial enterprises, fit into cities, whether there is a symbiosis with the external environment and whether such objects correspond to aesthetic, environmental, ergonomic 
requirements and what conditions are generally created in an industrial city : is it comfortable in it, how people feel in it, what kind of environment is created in it.

However, insufficient attention is paid to these issues so far, which in general hinders the development of the territory. In these conditions, gray city landscapes, conflict spaces, and an aesthetically and functionally poor environment force young ambitious people to act, transform their territory, but such practices are not always constructive and relevant to social attitudes.

Industrial premises located in cities that are not used in the life of ordinary citizens, with gray monotonous walls are prone to damage, vandalism more than other objects of the metropolis, modern facilities, significant cultural and social spaces also suffer. Vandalism, as "changing a part of the physical environment without the consent of its owner or manager" (Wise 1982) (and here we understand it more broadly than provided by the Criminal Code of the Russian Federation), is one of the typical phenomena in any modern metropolis. It is quite obvious that the causes of vandalism are not related to the purely personal characteristics of vandals (Kruzhkova, 2015), here the quality and specific configurations of the environment are of decisive importance $[3,4]$.

The modern city calls for vandalism. And here an interesting effect is observed: ecological contexts provoke vandalism, as a result, vandalism forms an unattractive appearance of the city, which, in turn, pushes young people to new destructive actions, a vicious circle arises. Obviously, the specific connection between vandalism and the quality of the urban environment largely determines the list of problems for the development of the territory and increasing its attractiveness, which makes us look for ways to analyze the possibilities of studying this aspect of the problem. In our opinion, an objective analysis is possible using the Integral deterministic index of vandal activity IVAOS (ObolenskayaSimonova Vandal Activity Index). The calculation of the index of vandal activity in the territory in connection with the price of real estate can show the level of opportunity costs for owners, whose assets are becoming cheaper due to the frightening social instability of vandalism.

The purpose of the presented study is to develop and substantiate the vandal activity index, as well as to consider the possibilities of IVAOS for assessing the territory, its attractiveness for living, doing business, investing, determining an effective strategy and formats for its development.

\section{Materials and Methods}

Determination of the parameters fixing the relationship between the presence of specific vandal damage and the quality of the territory required a comprehensive study of both the state of the external environment and a comprehensive analysis of the attitude of various categories of its users to the attractiveness of the territory in connection with the problem of vandalism. To achieve this goal, a large-scale study of vandalism was carried out in Yekaterinburg (an industrial, business, educational and cultural hub with 1.5 million inhabitants) in 2017-2019.

More than 6 thousand photos of vandal acts were recorded. In order to determine spatial triggers, cartography of vandal acts was carried out in connection with the types of buildings and the level of damage, as well as the remoteness of infrastructure facilities from the damaged areas.

At the second stage of the study, a survey of residents was conducted, aimed at determining the degree of significance of vandal damage in assessing the attractiveness of the environment for living, leisure, and tourism. The study involved 1504 Yekaterinburg residents. The respondents were asked to work with a Google form, no personal data was collected. The questions were in the form of visual and text cases; the survey also included 
a number of closed questions involving the identification of relevant criteria for assessing the territory, choosing a place of residence and recreation.

At the third stage of the study, 11 structured interviews were conducted with leading experts in the field of real estate sales from various real estate agencies in Yekaterinburg in order to concretize the data obtained during the survey of citizens, as well as to establish the characteristics of consumer behavior in the housing market due to vandal damage. All respondents were informed about the purpose of the study, interviews were conducted individually, and the process was recorded. All respondents were asked 20 open-ended questions. The main criterion for choosing the respondents was more than 5 years of experience in the field of real estate sales in Yekaterinburg. The participants were men and women from 30 to 35 years old.

\section{Results and Discussion}

Based on the processing of data from three sources, a number of dependencies were established, on the basis of which the index of vandal activity of ObolenskayaSimonovaIVAOS was determined.

- IVAOS The development of an index for each component of the study was carried out according to the general algorithm for calculating the summed Index as a simple mathematical sum of partial indices (Fig.1).
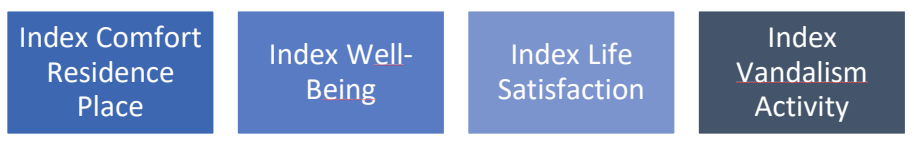

Fig. 1. Perception index of vandal activity

Curious results confirming the hypothesis about the influence of vandalism on the attractiveness of the territory and about the high significance of the vandal factor in assessing the commercial prospects of residential development, were obtained when analyzing the answers to a block of direct questions for the townspeople, formulated in the form of specific personal statements with which one could agree or disagree. fully or partially.

So, when answering the question "The presence of vandalism stops me when buying a home" $72 \%$ (40\% high probability $+32 \%$ categorically refuse to buy) of the respondents consider it inappropriate to purchase housing in areas with signs of vandal activity, which, of course, significantly reduces the competitiveness of such microdistricts and individual objects on the housing market in a metropolis, or requires ex-post costs to eliminate the consequences of vandal activities - painting over graffiti, repairing stops, benches and restoring trash cans, etc.

The setting "Drawings on city walls are beautiful" is close to more than $50 \%$ of the respondents, where $8 \%$ have a positive attitude towards most drawings, 34 often meet successful specimens. This indicates a certain aesthetic demand of the population and requires further research. Moreover, more than $20 \%$ experience anxiety from the presence of drawings.

The statement "I prefer to avoid areas with signs of vandalism .." in $62 \%$ causes partial or complete agreement, and only $4 \%$ do not worry about vandalism as a marker of insecurity.

The statement "My housing is cheaper if you see signs of neglect: broken bins, garbage, inscriptions" inspires agreement among $50 \%$ of the respondents, they believe that in this 
case they will have to make discounts for the sale. Only $8 \%$ of the respondents believe that this will not affect the price and speed of sale.

The statement "When choosing a district of residence, I take into account .." was disclosed by the maximum number of respondents through the provisions "cleanliness in the streets" - 70\%, "integrity of improvement elements" - 64\%, "neatness of urban objects" - $60 \%$, along with the presence of park zones and comfortable places for shopping. $18 \%$ pay attention to the painted walls, the figure is quite high, although lower than others from the vandal group.

It is interesting that when working with the statement "When I come to the city, I usually pay attention to .." the three most significant respondents also included cleanliness on the streets $-82 \%$, the integrity of the improvement elements $-60 \%$, the neatness of urban objects $-56 \%$, along with the presence of attractions $-62 \%$, which indicates a high value of the vandal factor for the tourist potential of the territory.

It has been established that when choosing a place of residence, townspeople choose, among other things, a place they perceive as safe. The definition of a socially dangerous place in $80 \%$ of cases includes the presence of scattered garbage and graffiti, in $100 \%$ of cases, broken, broken objects of improvement (benches, trash cans, lighting lanterns). The interviewed townspeople are also concerned about the content of the graffiti on the walls. If these are romantic messages, then, of course, a potential buyer regards this as neglect, and is also perceived as a marker of noise, but it is not an alarming sign of the marginalization of the territory. But obscene inscriptions, tagged (incomprehensible to a wide circle), and, especially, sites selling illegal substances are an alarming marker.

The IVAOS index was compiled on the basis of a survey of residents $(\mathrm{N}=1504)$ of Yekaterinburg in 2018-2019.

Questions were asked and photos were presented in order to determine the attitude towards the territory with signs of vandal activity in living conditions and a possible discount when buying with signs of vandalism on the building and the adjacent territory, as well as proposals for their cost estimate and the like without damage.

The respondents could rate each of the variants of the proposed photos on a scale from 1 to 5 . In each block, 6 variants of the photo were offered, the respondents could gain a maximum of 30 points.

The blocks represented photos with damaged landscaping elements, tagged graffiti, marketing, romantic, political, artistic.

The method of chain staging revealed the influence of each of the variants of vandal activity, as well as the total influence of all blocks in comparison with the assessment of comparable use cases without signs of vandal activity. Based on these data, the IVAOS index was formalized.

And also an acceptable corridor of values was determined, at which the presence of damage does not affect the cost or does not significantly affect. So, within the range from 0 to 0.2 , the respondents are ready to purchase housing, with the maximum values from 0.7 to 1.0 , they are categorically not ready to purchase, and if the IVAOS value is in the range from 0.3 to 0.7 , they are ready to buy when the presence of additional bonuses: discount, furniture, designer renovation, etc.

This influence on the index values in the territory allows us to talk about the possibilities of the situation, to control and maintain it at the level of a favorable one, demonstrated at the level of communication. This is especially true for work with youth vandalism, since it is the young who are most sensitive to changes in the city, and also show flexibility in the practice of self-exposure in the metropolis. Analysis of the photo base and cartographic data shows that open visited spaces provoke less vandal activity. Thus, secluded nooks, not adapted for leisure needs, are rarely observed by the presence of townspeople, turned out to be the most damaged. Young people use their city territory to 
enhance the ergonomics of space, painting bridges and fences, blank walls of technological booths for electricity, gas, heating networks, giving the city the appearance of a readable and understandable space. The study showed that the presence of infrastructure facilities in the courtyards reduces IVAOS. For example, sports grounds, workout equipment or even just bars and a horizontal bar reduce the Index by almost half (0.54), and the presence of modern playgrounds attractive for families with children provokes the constant presence of parents and grandmothers, grandfathers with children, increases the attendance of the courtyard and Reduces the Vandal Activity Index by $37 \%$. The opposite pattern with the presence of local retail outlets, old buildings with gray walls. The index of vandal activity is significantly higher than other places in the city (0.89). Schoolchildren express their feelings without leaving school, here are declarations of love, and tagged inscriptions, and broken objects of improvement.

In order to verify the survey data and obtain a more complete picture, 11 interviews were conducted with leading specialists of the city's real estate agencies, allowing to concretize the peculiarities of people's perception of vandalized urban environments through the analysis of the strategies of consumer behavior of citizens when buying and selling real estate.

When answering a group of questions, the main criterion for choosing housing is the absence of vandalism was named as the main factor, however, it was assumed that the state of the adjacent and adjacent territory, the micro district is important and is always included in the five main factors of choice. It is interesting that the majority of the respondents identify several basic strategies of consumer behavior: minimum requirements for the quality of the territory with a focus on a specific location; high requirements with a focus on low cost; high demands willingly pay for comfortable conditions (including clients focused on exclusive, elite housing). It is noted that the first strategy has been encountered less and less in recent years, and mainly the focus on a quality environment prevails. A high-quality environment adjacent to the environment is defined through the concepts of "safety", "comfort", "image", "prestige":

"The new fund has infill and complex buildings; some are scared off by the nearby barracks. People more often want to buy housing in such a complex when everything is there, a different environment. They are guided by this immediately. We distinguish 2 categories of people who value, choose only good options, $80 \%$ of those who appreciate. They look at the state of the common areas in the house, in the yard. People now more and more strive to improve their living standards, to live in a comfortable environment when moving ...".

"Now the culture of life has been formed, it is obvious! If earlier housing was given out and there was no choice, then this

\section{Conclusions}

Modern regional development is impossible without taking into account the conditions of new industrialization in various microdistricts of settlements. The center and microdistricts of complex development in cities bring the real appearance of the city closer to the created image of an ideal modern place for life and business. However, others - microdistricts of Khrushchev, Brezhnev, Stalinist buildings, nine-story panel buildings do not correspond to the ideal image of a modern place of residence. This situation leads to an increase in stress factors of the urban environment, which is already significant in industrial cities. The growth in the number of stress factors forces the townspeople to change the image of the city at their own discretion, transform the environment to adapt it to themselves (Kruzhkova O.V. 2015) [4]. Financially secure young people try to leave such areas, which only worsens the situation, as the middle class is being washed out. The territory is being 
marginalized. The process develops in a spiral: the higher the level of vandalism, the faster the territory is marginalized. To control negative trends, an integrated approach is required, including preventive measures based on an accurate assessment of the current state of the territories.

The city requires expenses for maintaining comfortable living conditions and doing business, including the costs of eliminating the consequences of vandal activity. Modern megalopolis development should take into account how new objects fit into the city space (Obolenskaya A.G., Karimova V.G., 2017) [5]. Regular painting of graffiti by utilities does not help; a freshly painted wall becomes an excellent canvas for new inscriptions (I.A. Simonova, 2019) [6]. However, under the condition of ergonomic development, competent location of infrastructure facilities, maintenance of the territory in a condition stipulated by the rules for the improvement of each municipal entity, state that does not provoke vandal activity, will reduce the imputed costs of property owners and, in general (Brunes F. et al., 2020; Umar A. S., 2019; Dziauddin M. F., Idris Z., 2018), will increase the attractiveness and competitiveness of the territory $[7,8,9]$.

Thus, the index of vandal activity in the territory can be used for express diagnostics of the potential of the territory and its investment attractiveness in terms of the real estate market. So, with a threatening IVAOS, it is necessary to plan adequate response measures, otherwise the attractiveness of the territory will be inferior to its competitors, and the real estate market may stagnate.

\section{Acknowledgements}

This research was supported by Russian Science Foundation (Project No 17-18-01278).

\section{References}

1. O.S. Emmanuel, M.A Lizam, Journal of Engineering and Applied Sciences, 5, 1205 (2017)

2. S. Weber et al., Landscape and Urban Planning, 167, 147 (2017)

3. J. Wise, Psychology Today, 9, 28 (1982)

4. O.V. Kruzhkova, From the origins to the present 130 years of the organization of the psychological society at Moscow University: collection of materials of the anniversary conference in 5 volumes, 325 (2015)

5. A.G. Obolenskaya, V.G. Karimova, Human development in the modern world, 2, 88 (2017)

6. I.A. Simonova, Monitoring of public opinion: Economic and social changes, 1, 273 (2019)

7. F. Brunes et al, Journal of European Real Estate Research (2020)

8. A.S. Umar, ETSJ, 2 (2019)

9. M. F. Dziauddin, Z. Idris, Pacific Rim Property Research Journal, 1, 49 (2018) 